\title{
Work Characteristics of Acute Care Surgeons at a Swiss Tertiary Care Hospital: A Prospective One-Month Snapshot Study
}

\author{
Claudine Di Pietro Martinelli ${ }^{1}$ (1) $\cdot$ Tobias Haltmeier $^{1} \cdot$ Joël L. Lavanchy $^{1} \cdot$ Stéphanie F. Perrodin $^{1}$ • \\ Daniel Candinas $^{1} \cdot$ Beat Schnüriger ${ }^{1}$
}

Accepted: 2 October 2021 / Published online: 22 October 2021

(C) The Author(s) 2021

\begin{abstract}
Background Multiple acute care surgery (ACS) working models have been implemented. To optimize resources and on-call rosters, knowledge about work characteristics is required. Therefore, this study aimed to investigate the daily work characteristics of ACS surgeons at a Swiss tertiary care hospital.

Methods Single-center prospective snapshot study. In February 2020, ACS fellows prospectively recorded their work characteristics, case volume and surgical case mix for 20 day shifts and 16 night shifts. Work characteristics were categorized in 11 different activities and documented in intervals of $30 \mathrm{~min}$. Descriptive statistics were applied. Results A total of 432.5 working hours (h) were documented and characterized. The three main activities 'surgery,' 'patient consultations' and 'administrative work' ranged from 30.8 to $35.9 \%$ of the documented working time. A total of 46 surgical interventions were performed. In total, during day shifts, there were 16 elective and 15 emergency interventions, during night shifts 15 emergency interventions. For surgery, two peaks between 10:00 a.m.-02:00 p.m. and 08:00 p.m.-11:00 p.m. were observed. A total of 225 patient were consulted, with a first peak between 08:00 a.m. and 11:00 a.m. and a second, wider peak between 02:00 p.m. and 02:00 a.m.

Conclusion The three main activities 'surgery,' 'patient consultations' and 'administrative work' were comparable with approximately one third of the working time each. There was a bimodal temporal distribution for both surgery and patient consultations. These results may help to improve hospital resources and on-call rosters of ACS services.
\end{abstract}

\section{Introduction}

Conceived in 2003 in Northern America, the concept of acute care surgery (ACS) is globally evolving. Encompassing emergency general surgery (EGS), trauma surgery and surgical critical care, the implementation of an ACS service has shown to improve efficacy in the management of various surgical emergencies [1-4].

Beat Schnüriger

beat.schnuriger@gmail.com

1 Department of Visceral Surgery und Medicine, Inselspital, Bern University Hospital, University of Bern, Bern, Switzerland
Recognizing the specific needs, time sensitiveness of treatment, and complexity of patients with abdominal surgical emergencies, an ACS service has been established at Bern University Hospital in 2016. Bern University Hospital is a tertiary care facility with a catchment area of approximately one million people. Annually, around 750 EGS procedures are carried out at Bern University Hospital. Within the Department of Visceral Surgery and Medicine, the ACS team takes responsibility for 24 h EGS interventions and consultations Monday through Friday. On weekends, additional staff from other surgical subspecialties (i.e., colorectal, hepatobiliary) from the Department of Visceral Surgery and Medicine are taking calls.

In addition to EGS procedures, the ACS team does consultations for patients with acute traumatic or non- 
traumatic abdominal disease in the emergency department (ED), intensive care unit (ICU), on regular wards and outpatient clinics of Bern University Hospital. Moreover, the ACS team closely follows critically ill patients with abdominal diseases on the ICU daily, in collaboration with intensive care specialists. Elective procedures, such as cholecystectomies, hernia repairs, colorectal procedures for benign diseases (i.e. subsequent colostomy takedown) and planned re-laparotomies, are also part of the daily routine of the ACS team.

Whereas an increasing number of ACS working models have been implemented and further developed worldwide [5-9], no data are available about the daily practice of ACS surgeons in Switzerland. To optimize hospital resources and on-call rosters, knowledge about work characteristics and distribution is required. Therefore, this study aimed to investigate for the first time the daily work characteristics of ACS surgeons at a Swiss tertiary care hospital, taking into account both the characteristics and timely distribution of the work activity.

\section{Material and methods}

At the Department of Visceral Surgery and Medicine at Bern University, there is a designated Acute Care Surgery Team in place, including three ACS fellows and four surgical residents that work under the supervision of an attending surgeon specialized in the field of ACS. These fellows are board-certified general surgeons and are in their further training to become specialists in visceral surgery. The fellows from the entire department rotate into the ACS Team for at least 6 months to further train and improve their skills and knowledge on the broad care of acute surgical patients. A senior attending ACS surgeon very closely supervises and teaches them. In addition, the organ specific specialists (upper gastrointestinal surgery, hepatobiliary surgery, etc.) are consulted as needed.

ACS fellows work in a two-shift system. A day shift lasts from 07:30 a.m. to 05:00 p.m. $(9.5 \mathrm{~h})$ and the night shift from 05.00 p.m. until 07.30 a.m. (14.5 h), respectively. Attendance time is mandatory during the day shift, whereas ACS fellows are on-call at night.

From February 1 to February 29, 2020, three ACS fellows prospectively documented detailed data regarding the characteristics of their work, case volume and surgical case mix in intervals of 30 min for a total of 20 day shifts and 16 night shifts.

Collected data were grouped into three main categories and 11 subcategories: Surgery (elective and emergency surgery), Patient consultations (on regular wards, ICU, ED or outpatient clinic) and administrative work (morning reports, board participation, research, teaching and office work). Specifically during the night shift, the time being solely on-call without presence in the operating room (OR) or patient consultations or administrative work was documented as such.

Descriptive statistics were applied. Categorical variables are documented as numbers and percentages, and continuous variables including times are given as median and ranges.

\section{Results}

In February 2020, during 20 day and 16 night shifts, a total of 432.5 working hours $(h)$, (198.5 h during day shifts, $234.0 \mathrm{~h}$ during night shifts) were prospectively documented and characterized by a total of three ACS fellows. The activity profiles, stratified according to day or night shifts, are outlined in Table 1 . The three main activities 'surgery,' 'patient consultations' and 'administrative work' were comparable with $30.8-35.9 \%$ of the documented working time. Additionally, at night shifts, the fellows were in-house for a median of $8.3 \mathrm{~h}$ (range 5.0-16.5 h) and on-call (without specific activity) for a median of $6.5 \mathrm{~h}$ (range 1.5-9.5 h).

A total of 46 surgical interventions were performed by the three ACS fellows during the documented study period of 20 days and 16 nights. During the day shifts, there were 16 elective and 15 emergency interventions and 15 emergency interventions during night shifts. These surgical interventions are outlined in Table 2. Most frequent emergency surgical interventions were diagnostic laparoscopies and laparotomies for intestinal perforation $(n=7)$, laparoscopic appendectomies $(n=6)$ and laparoscopic cholecystectomies $(n=5)$. Most frequent elective surgical interventions included hernia surgery $(n=6)$ and laparoscopic cholecystectomies $(n=3)$. Regarding temporal distribution of surgery, there was a first peak between 10:00 a.m. and 02:00 p.m. and a second peak between 08:00 p.m. and 11:00 p.m. (Fig. 1).

During the study period, a total of 225 patient consultations were performed. Thereof, 124 (55\%) consultations were carried out during the day shifts and $101(45 \%)$ consultations during the night shifts. Of the 225 patient consultations, $92(41 \%)$ were performed on surgical, orthopedic and various nonsurgical wards, 68 (30\%) in the ED and $65(29 \%)$ in the outpatient clinic. Figure 2 demonstrates the temporal distribution of patient consultations. The daily scheduled ICU and ward rounds resulted in a first sharp peak of consultations between 08:00 a.m. and 11:00 a.m. Moreover, there was a second wider peak between 02:00 p.m. and 02:00 a.m. with predominantly consultations in the ED and regular wards. Between 04:00 
Table 1 Activity profile of ACS fellows

\begin{tabular}{|c|c|c|c|c|c|c|c|c|c|}
\hline & \multicolumn{3}{|l|}{ Total } & \multicolumn{3}{|l|}{ Day shift } & \multicolumn{3}{|c|}{ Night shift } \\
\hline & Median* & Range & $(\%)$ & Median* & Range & $(\%)$ & Median & Range * & $(\%)$ \\
\hline Surgery & 3.3 & $0.5-11.0$ & $(33.3)$ & 2.5 & $0.5-11.0$ & $(27.8)$ & 3.5 & $0.5-6.0$ & $(35.0)$ \\
\hline Elective surgery & 3.5 & $0.5-4.5$ & & 3.5 & $0.5-4.5$ & & - & - & \\
\hline Emergency surgery & 2.5 & $0.5-7.0$ & & 1.5 & $0.5-7.0$ & & 3.5 & $0.5-6.0$ & \\
\hline Patient consultations & 3.5 & $0.5-6.5$ & (35.9) & 3.3 & $0.5-6.5$ & $(36.1)$ & 3.5 & $0.5-6.5$ & $(35.0)$ \\
\hline Regular ward & 2.0 & $0.5-3.0$ & & 2.0 & $0.5-3.0$ & & 2.3 & $0.5-2.5$ & \\
\hline ED and shockroom & 1.0 & $0.5-3.5$ & & 1.0 & $0.5-3.5$ & & 1.0 & $1.0-3.5$ & \\
\hline Outpatient clinic & 1.0 & $0.5-4.0$ & & 1.0 & $0.5-4.0$ & & - & - & \\
\hline ICU & 0.5 & $0.5-3.5$ & & 0.5 & $0.5-3.5$ & & 0.8 & $0.5-3.5$ & \\
\hline Administrative work & 3.0 & $0.5-7.5$ & $(30.8)$ & 3.3 & $0.5-7.5$ & $(36.1)$ & 3.0 & $1.0-7.5$ & $(30.0)$ \\
\hline Office work & 2.5 & $0.0-5.5$ & & 2.5 & $0.0-5.5$ & & 2.5 & $0.5-5.5$ & \\
\hline Research & 1.8 & $1.0-3.5$ & & 1.3 & $1.0-3.5$ & & 2.0 & $1.0-3.5$ & \\
\hline Teaching & 1.0 & $1.0-1.0$ & & 1.0 & $1.0-1.0$ & & 1.0 & $1.0-1.0$ & \\
\hline Board & 1.0 & $0.5-1.5$ & & 1.0 & $0.5-1.5$ & & 0.5 & $0.5-0.5$ & \\
\hline On-call time & - & - & $(-)$ & - & - & $(-)$ & 6.5 & $1.5-9.5$ & $(-)$ \\
\hline
\end{tabular}

*Medians are reported as hours per day $(24 \mathrm{~h})$

$A C S$ : Acute Care Surgery; ED: Emergency Department; $I C U$ : Intensive Care Unit

Table 2 Surgical case mix

\begin{tabular}{|c|c|c|c|c|c|c|c|c|}
\hline & \multirow{2}{*}{\multicolumn{2}{|c|}{ Total }} & \multicolumn{4}{|c|}{ Day shift } & \multirow{2}{*}{\multicolumn{2}{|c|}{$\frac{\text { Night shift }}{\text { Emergency }}$}} \\
\hline & & & \multicolumn{2}{|c|}{ Elective } & \multicolumn{2}{|c|}{ Emergency } & & \\
\hline & $n$ & $(\%)$ & $n$ & $(\%)$ & $n$ & $(\%)$ & $n$ & $(\%)$ \\
\hline Cholecystectomy & 8 & $(17.4)$ & 3 & $(6.5)$ & 2 & $(4.4)$ & 3 & $(6.5)$ \\
\hline Intestinal perforation & 7 & $(15.3)$ & - & $(-)$ & 2 & (4.4) & 5 & $(10.8)$ \\
\hline Appendectomy & 6 & $(13.0)$ & - & $(-)$ & 4 & (8.6) & 2 & $(4.4)$ \\
\hline Hernia surgery & 6 & $(13.0)$ & 6 & $(13.0)$ & - & $(-)$ & - & $(-)$ \\
\hline i.v.-ports and catheters & 5 & $(10.9)$ & 2 & $(4.4)$ & 3 & (6.4) & - & $(-)$ \\
\hline Intestinal obstruction & 4 & $(8.7)$ & - & $(-)$ & 1 & $(2.2)$ & 3 & $(6.5)$ \\
\hline Proctology & 3 & $(6.5)$ & 1 & $(2.2)$ & 2 & (4.4) & - & $(-)$ \\
\hline Mesenteric ischemia & 1 & $(2.2)$ & - & $(-)$ & - & $(-)$ & 1 & $(2.2)$ \\
\hline Other (including trauma) & 6 & $(13.0)$ & 4 & (8.7) & 1 & $(2.2)$ & 1 & $(2.2)$ \\
\hline Total & 46 & (100) & 16 & (34.8) & 15 & (32.6) & 15 & (32.6) \\
\hline
\end{tabular}

a.m. and 08:00 a.m. a very low number of patient consultations were performed.

\section{Day shift (07:30 a.m. to 05:00 p.m.)}

During the day shift of a total of $9.5 \mathrm{~h}$, surgery accounted for a median of $2.5 \mathrm{~h}$ (range $0.5-11.0 \mathrm{~h}$ ). These included $3.5 \mathrm{~h}$ (range $0.5-4.5 \mathrm{~h}$ ) elective and $1.5 \mathrm{~h}$ (range $0.5-7.0 \mathrm{~h}$ ) EGS procedures. Patient consultations accounted for a median of $3.3 \mathrm{~h}$ (range $0.5-6.5 \mathrm{~h}$ ). These comprised of consultations on the wards [2.0 h (range 0.5-3.0 h)], ED and shock room [1.0 h (range 0.5-3.5 h)], outpatient clinic $[1.0 \mathrm{~h}$ (range $0.5-4.0 \mathrm{~h}$ ) $]$ and ICU $[0.5 \mathrm{~h}$ (range 0.5-3.5 h)]. Administrative work accounted for a median of $3.3 \mathrm{~h}$ (range $0.5-7.5 \mathrm{~h}$ ).

These included office work [2.5 h (range 0.0-5.5 h)], research $[1.3 \mathrm{~h}$ (range $1.0-3.5 \mathrm{~h})]$, morning reports and tumor or trauma board participations $[1.0 \mathrm{~h}$ (range $0.5-1.5 \mathrm{~h})]$ and teaching [1.0 h (range 1.0-1.0 h)]. 
Fig. 1 Temporal distribution of surgery
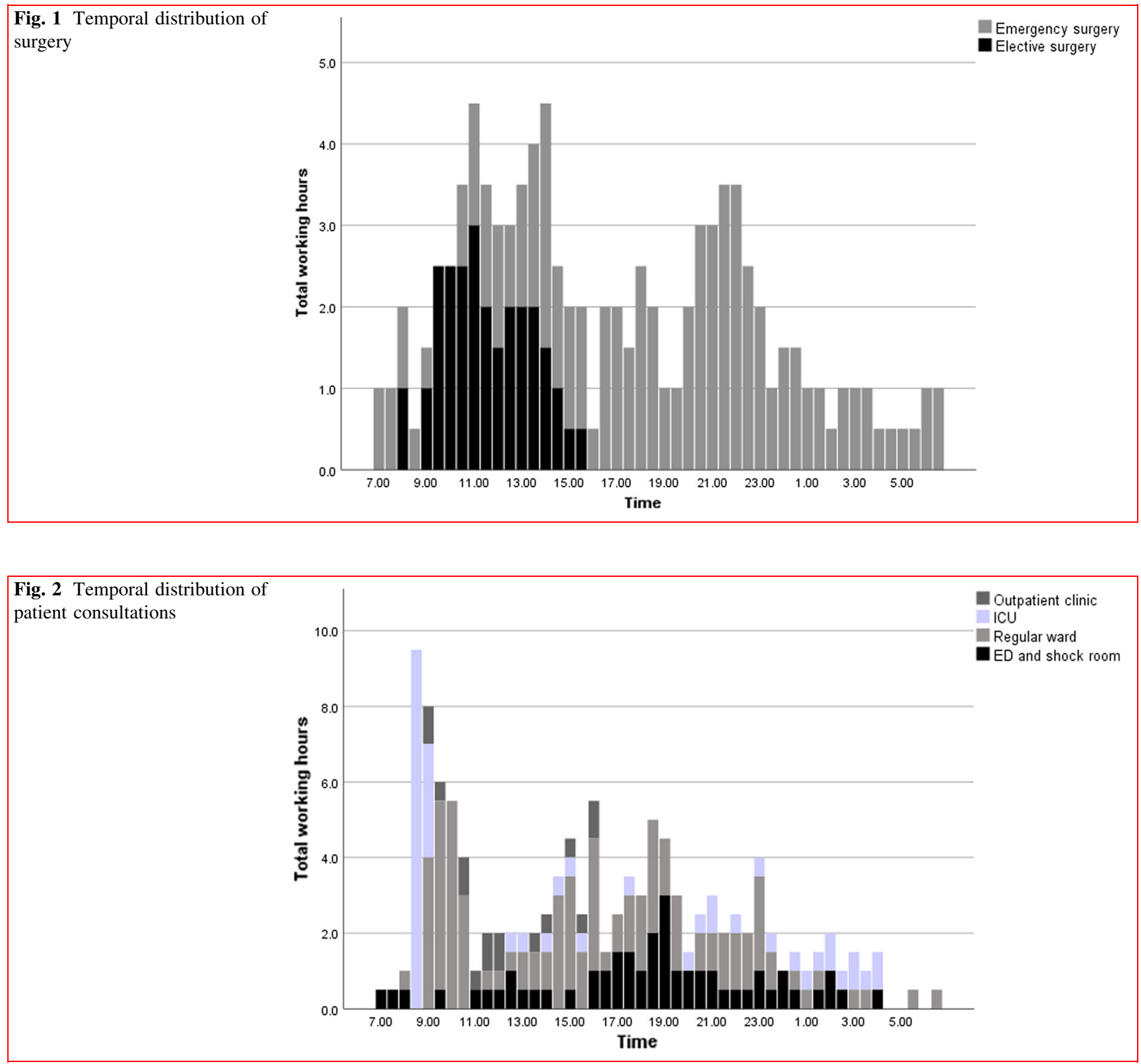

\section{Night shift (05:00 p.m. to 07:30 a.m.)}

During the night shift of a total of $14.5 \mathrm{~h}$, the ACS fellows were working in-house for a median of $8.3 \mathrm{~h}$ (range 5.0-16.5 h) and on-call without specific activity for a median of $6.5 \mathrm{~h}$ (range 1.5-9.5 h). Of working time at night, emergency surgery accounted for a median of $3.5 \mathrm{~h}$ (range 0.5-6.0 h). No elective interventions were performed at night. Patient consultations accounted for a median of $3.5 \mathrm{~h}$ (range $0.56 .5 \mathrm{~h}$ ). These included consultations on the wards [2.3 $\mathrm{h}$ (range $0.5-2.5 \mathrm{~h}$ )], ICU [0.8 h (range 0.5-3.5 h)] and ED and shock room [1.0 h (range 1.0-3.5 h)]. No 'elective' consultations in the outpatient clinic were performed during the night shift. Administrative work accounted for a median of $3.0 \mathrm{~h}$ (range 1.0-7.5 h). These included morning reports and tumor or trauma board participations $[0.5 \mathrm{~h}$ (range $0.5-0.5 \mathrm{~h}$ )], research [2.0 h (range 1.0-3.5 h)], teaching [1.0 $\mathrm{h}$ (range 1.0-1.0 h)] and office work [2.5 h (range $0.5-5.5 \mathrm{~h})]$. 


\section{Discussion}

This study investigated the daily work characteristics of ACS surgeons at a Swiss tertiary care hospital, taking into account both the characteristics and temporal distribution of the activities. Currently, no similar investigations are available. The three main activities 'surgery,' 'patient consultations' and 'administrative work' were comparable taking up approximately one third of the documented working time each. There was a bimodal temporal distribution for both surgery and patient consultations. Between 04:00 a.m. and 08:00 a.m. workload settled due to reduced patient consultations and surgical interventions.

In 2006, ACS has been implemented in the USA with great success regarding clinical outcomes, optimization of acute patient's care, research knowledge and surgical satisfaction [10-14]. However, little data are available on the details of the daily work characteristics of ACS fellows $[15,16]$.

In February 2020, a snapshot of working practice before the COVID-19 pandemic could be achieved. Of note, the number of surgical interventions was somewhat below the calculated median, taking into account the overall 744 emergent abdominal surgical interventions that were performed in 2020 at Bern University Hospital. However, the number of EGS interventions was comparable to other centers with similar size and characteristics [17, 18].

In contrast to the number and characteristics of EGS interventions, little is known about the amount of patient consultations and required administrative work. In the current study, pre- and postoperative care, as well as the management of non-operatively treated patients, occupied a third of the overall working time. This considerable amount of non-operative working time reflects the ACS model, where the assessment of acute patients or close follow-up of conservatively treated patients plays a major role. Moreover, the presence of the ACS surgeon in the ICU is of great importance to provide optimal interdisciplinary treatment of critically ill surgical patients [19-21].

Administrative work is considerable and is related to various tasks such as billing and insurance-related paperwork, as well as for medico-legal requirements [22, 23]. Careful monitoring of the development of the time-consuming administrative component of our work is required to avoid further increase. The bimodal distribution of surgery is related to the elective caseload at day shifts, the operating room resources and prioritization of emergency interventions. At Bern University Hospital, there is a des- ignated OR for patients with an expected serious adverse outcome if not operated on within six hours. The remaining patients undergo surgical intervention after or in between the elective surgical procedures. A considerable amount of emergent surgical interventions is performed between 08:00 p.m. and 11:00 p.m. This needs to be taken into account when planning and scheduling teams of ACS teams. Patients' consultations first peaked in the morning due to scheduled daily rounds on ICU and wards. A second wider peak was found and is reflecting a more continuous demand for acute surgical assessment and care from 02:00 p.m. to 02:00 a.m. with predominantly consultations in the ED, shockroom and wards. This bimodal distribution underlines the importance of the presence of ACS fellows for the evaluation of patients throughout the entire institution at any time. The timely acute assessment and troubleshooting of patients are of paramount importance and has a direct impact on patients' outcomes [10, 24-27].

In 2015, Pottenger et al. analyzed frequency counts and work relative value units generated for specific codes to characterize the average trauma and emergency surgeon's work experience over time in the USA.

These investigators found that acute care surgery consists of $40 \%$ surgical and $60 \%$ cognitive work [28]. Similar to these findings, the current prospective snapshot study showed that a considerable part of the daily routine of acute care surgeons consists of non-procedural work, whether this amount of non-operative skills is larger than in other surgical subspecialties is uncertain and warrants further investigations.

\section{Conclusion}

At the investigated Swiss tertiary care center, the workload of ACS surgeons includes mainly EGS interventions, preand postoperative patient consultations, non-operative patient management and administrative work. Both broad general surgical and cognitive skills should be implemented into adapted training programs to meet the unique and challenging requirements of acute care surgery.

Author contributions BS contributed to conception of the study and drafting of the manuscript. CDPM contributed to analysis and drafting of the manuscript. TH contributed to analysis and drafting of the manuscript. JL contributed to data collection and critical revision. SFP contributed to data collection and critical revision. DC contributed to critical revision. 
Funding Open access funding provided by University of Bern.

\section{Declarations}

Conflict of interest The authors report no conflicts of interest relevant to this article and received no specific funding. Ethical approval omitted due to the study design.

Open Access This article is licensed under a Creative Commons Attribution 4.0 International License, which permits use, sharing, adaptation, distribution and reproduction in any medium or format, as long as you give appropriate credit to the original author(s) and the source, provide a link to the Creative Commons licence, and indicate if changes were made. The images or other third party material in this article are included in the article's Creative Commons licence, unless indicated otherwise in a credit line to the material. If material is not included in the article's Creative Commons licence and your intended use is not permitted by statutory regulation or exceeds the permitted use, you will need to obtain permission directly from the copyright holder. To view a copy of this licence, visit http://creativecommons. org/licenses/by/4.0/.

\section{References}

1. Chana P, Burns EM, Arora S, Darzi AW, Faiz OD (2016) A systematic review of the impact of dedicated emergency surgical services on patient outcomes. Ann Surg 263(1):20-27. https://doi. org/10.1097/sla.0000000000001180

2. Barnes SL, Cooper CJ, Coughenour JP, MacIntyre AD, Kessel JW (2011) Impact of acute care surgery to departmental productivity. J Trauma 71(4):1027-32. https://doi.org/10.1097/TA. 0b013e3182307146

3. Jurkovich GJ, Davis KA, Burlew CC, Dente CJ, Galante JM, Goodwin JS 2nd et al (2017) Acute care surgery: an evolving paradigm. Curr Probl Surg 54(7):364-395. https://doi.org/10. 1067/j.cpsurg.2017.05.001

4. To KB, Kamdar NS, Patil P, Collins SD, Seese E, Krapohl GL et al (2019) Acute care surgery model and outcomes in emergency general surgery. J Am Coll Surg 228(1):21-8.e7. https:// doi.org/10.1016/j.jamcollsurg.2018.07.664

5. Santry HP, Madore JC, Collins CE, Ayturk MD, Velmahos GC, Britt LD et al (2015) Variations in the implementation of acute care surgery: results from a national survey of university-affiliated hospitals. J Trauma Acute Care Surg 78(1):60-7. https://doi. org/10.1097/ta.0000000000000492

6. Sarmiento Altamirano D, Himmler A, Chango Siguenza O, Pino Andrade R, Flores Lazo N, Reinoso Naranjo J et al (2020) The successful implementation of a trauma and acute care surgery model in ecuador. World J Surg. https://doi.org/10.1007/s00268020-05435-z

7. Hsee L, Devaud M, Middelberg L, Jones W, Civil I (2012) Acute surgical unit at Auckland City hospital: a descriptive analysis. ANZ J Surg 82(9):588-591. https://doi.org/10.1111/j.14452197. 2012.06141.x
8. Khubchandani JA, Ingraham AM, Daniel VT, Ayturk D, Kiefe CI, Santry HP (2018) Geographic diffusion and implementation of acute care surgery: an uneven solution to the national emergency general surgery crisis. JAMA Surg 153(2):150-159. https://doi.org/10.1001/jamasurg.2017.3799

9. Koea JB, Srinivasa S, Hundal H (2014) Provision of acute general surgery: a systematic review of models of care. J Trauma Acute Care Surg 76(1):219-225. https://doi.org/10.1097/TA. 0b013e3182a92481

10. Vergis A, Metcalfe J, Stogryn SE, Clouston K, Hardy K (2019) Impact of acute care surgery on timeliness of care and patient outcomes: a systematic review of the literature. Canadian J Surg 62(4):281-288. https://doi.org/10.1503/cjs.010718

11. Nagaraja V, Eslick GD, Cox MR (2014) The acute surgical unit model verses the traditional "on call" model: a systematic review and meta-analysis. World J Surg 38(6):1381-1387. https://doi. org/10.1007/s00268-013-2447-1

12. O'Mara MS, Scherer L, Wisner D, Owens LJ (2014) Sustainability and success of the acute care surgery model in the nontrauma setting. J Am Coll Surg 219(1):90-98. https://doi.org/10. 1016/j.jamcollsurg.2014.02.022

13. Baroutjian A, Sutherland M, Hoff JJ, Bean T, Sanchez C, McKenney M et al (2021) The impact of hospital/university affiliation on research productivity among US-based authors in the fields of Trauma, surgical critical care, acute care, and emergency general surgery. Am Surg 87(1):30-38. https://doi. org/10.1177/0003134820949508

14. DeGirolamo K, Murphy PB, D’Souza K, Zhang JX, Parry N, Haut E et al (2017) Processes of health care delivery, education, and provider satisfaction in acute care surgery: a systematic review. Am Surg 83(12):1438-1446

15. Garland AM, Riskin DJ, Brundage SI, Moritz F, Spain DA, Purtill MA et al (2007) A county hospital surgical practice: a model for acute care surgery. Am J Surg 194(6):758-63. https:// doi.org/10.1016/j.amjsurg.2007.08.019

16. van der Wee MJL, van der Wilden G, Hoencamp R (2020) Acute care surgery models worldwide: a systematic review. World J Surg 44(8):2622-2637. https://doi.org/10.1007/s00268-02005536-9

17. van Zyl TJ, Murphy PB, Allen L, Parry NG, Leslie K, Vogt KN (2018) Beyond just the operating room: characterizing the complete caseload of a tertiary acute care surgery service. Canadian J Surg 61(4):7417. https://doi.org/10.1503/cjs.007417

18. Matsushima K, Cook A, Tollack L, Shafi S, Frankel H (2011) An acute care surgery model provides safe and timely care for both trauma and emergency general surgery patients. J Surg Res 166(2):e143-e147. https://doi.org/10.1016/j.jss.2010.11.922

19. Ivy M, Angood P, Kirton O, Shapiro M, Tisherman S, Horst M (2000) Critical care medicine education of surgeons: recommendations from the surgical section of the society of critical care medicine. Crit Care Med 28(3):879-880. https://doi.org/10.1097/ 00003246-200003000-00044

20. Tisherman SA, Kaplan L, Gracias VH, Beilman GJ, Toevs C, Byrnes MC et al (2013) Providing care for critically ill surgical patients: challenges and recommendations. JAMA Surg 148(7):669-674. https://doi.org/10.1001/jamasurg.2013.1208

21. Pelosi P, Ball L, Schultz MJ (2018) How to optimize critical care resources in surgical patients: intensive care without physical 
borders. Curr Opin Crit Care 24(6):581-587. https://doi.org/10. 1097/mcc.0000000000000557

22. Woolhandler S, Himmelstein DU (2014) Administrative work consumes one-sixth of US physicians' working hours and lowers their career satisfaction. Int $\mathbf{J}$ Health Serv Plan Adm Eval 44(4):635-42. https://doi.org/10.2190/HS.44.4.a

23. Hawkins M (2018) survey of america's physicians: Practice patterns and perspectives. In: The Physicians Foundation. 2018. https://physiciansfoundation.org/wpcontent/uploads/2018/09/phy sicians-survey-results-final-2018.pdf

24. Cubas RF, Gómez NR, Rodriguez S, Wanis M, Sivanandam A, Garberoglio CA (2012) Outcomes in the management of appendicitis and cholecystitis in the setting of a new acute care surgery service model: impact on timing and cost. J Am Coll Surg 215(5):715-721. https://doi.org/10.1016/j.jamcollsurg.2012.06. 415

25. Lau B, Difronzo LA (2011) An acute care surgery model improves timeliness of care and reduces hospital stay for patients with acute cholecystitis. Am Surg 77(10):1318-1321

26. Ricci KB, Rushing AP, Ingraham AM, Daniel VT, Paredes AZ, Diaz A et al (2019) The association between self-declared acute care surgery services and operating room access: results from a national survey. J Trauma Acute Care Surg 87(4):898-906. https://doi.org/10.1097/ta.0000000000002394

27. Daniel VT, Rushing AP, Ingraham AM, Ricci KB, Paredes AZ, Diaz A et al (2019) Association between operating room access and mortality for life-threatening general surgery emergencies. J Trauma Acute Care Surg 87(1):35-42. https://doi.org/10.1097/ ta.0000000000002267

28. Pottenger BC, Galante JM, Wisner DH (2015) The modern acute care surgeon: characterization of an evolving surgical niche.
J Trauma Acute Care Surg 78(1):120-125. https://doi.org/10. 1097/ta.0000000000000496

Publisher's Note Springer Nature remains neutral with regard to jurisdictional claims in published maps and institutional affiliations.

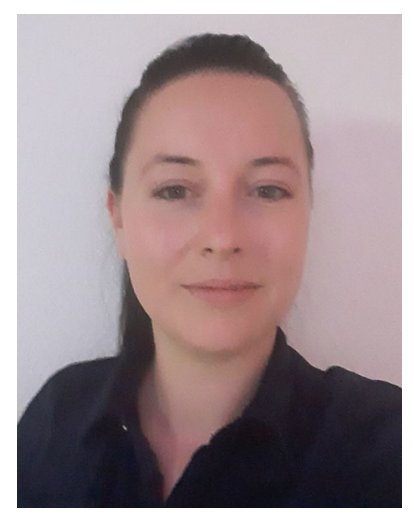

Claudine Di Pietro Martinelli was born and raised in Switzerland. After obtaining her medical degree from University Hospital of Zurich, Switzerland, she completed her surgical common trunk training at the Triemli Municipal Hospital of Zurich, Switzerland. She then joined the Department for Visceral Surgery and Medicine of Inselspital, University Hospital of Bern, Switzerland, to continue her surgical residency training. There she was able to combine her clinical interest with clinical research, where her focus lies in emergency abdominal surgery. Besides surgery, she is an avid indoor climber and has a passion for bouldering. 